Journal for ImmunoTherapy of Cancer

\section{CXCL13 shapes immunoactive tumor microenvironment and enhances the efficacy of PD-1 checkpoint blockade in high-grade serous ovarian cancer}

To cite: Yang M, Lu J, Zhang G, et al. CXCL13 shapes immunoactive tumor microenvironment and enhances the efficacy of PD-1 checkpoint blockade in high-grade serous ovarian cancer. Journal for ImmunoTherapy of Cancer 2021;9:e001136. doi:10.1136/ jitc-2020-001136

- Additional material is published online only. To view, please visit the journal online (http://dx.doi.org/10.1136/jitc2020-001136).

MY, JL and GZ contributed equally.

Accepted 11 December 2020

Check for updates

(C) Author(s) (or their employer(s)) 2021. Re-use permitted under CC BY-NC. No commercial re-use. See rights and permissions. Published by BMJ.

${ }^{1}$ Shanghai Key Laboratory of Female Reproductive Endocrine Related Diseases, Obstetrics and Gynecology Hospital of Fudan University, Shanghai, China ${ }^{2}$ Department of Biochemistry and Molecular Biology, Fudan University School of Basic Medical Sciences, Shanghai, China

Correspondence to Dr Haiou Liu;

liuhaiou@fudan.edu.cn

Professor Congjian Xu; xucongjian@fudan.edu.cn

\section{ABSTRACT}

Background Most patients with high-grade serous ovarian cancer (HGSC) lack an effective response to immune checkpoint blockade, highlighting the need for more knowledge about what is required for successful treatment. As follicular cytotoxic CXCR5 ${ }^{+} \mathrm{CD}^{+} \mathrm{T}$ cells are maintained by reinvigoration by immune checkpoint blockade in tumors, we attempted to reveal the relationship between $\mathrm{CXCR}^{+} \mathrm{CD} 8^{+} \mathrm{T}$ cells and the tumor microenvironment to predict immunotherapy responses in HGSC.

Methods 264 patients with HGSC from two cohorts and 340 HGSC cases from The Cancer Genome Atlas cohort were enrolled. Ex vivo and in vivo studies were conducted with human HGSC tumors and murine tumor models.

The spatial correlation between CXC-chemokine ligand 13 (CXCL13), CXCR5, CD8, and CD20 was evaluated by immunohistochemistry and immunofluorescence. Survival was compared between different subsets of patients using Kaplan-Meier analysis. The therapeutic effect of CXCL13 and programmed cell death-1 (PD-1) blockade was validated using human HGSC tumors and murine models. Results High CXCL13 expression was associated with prolonged survival. Tumors with high CXCL13 expression exhibited increased infiltration of activated and CXCR5expressing $\mathrm{CD}^{+} \mathrm{T}$ cells. Incubation with $\mathrm{CXCL13}$ facilitated expansion and activation of $\mathrm{CXCR} 5^{+} \mathrm{CD} 8^{+} \mathrm{T}$ cells ex vivo. $\mathrm{CXCR} 5^{+} \mathrm{CD} 8^{+} \mathrm{T}$ cells appeared in closer proximity to CXCL13 in tumors and chemotaxis towards CXCL13 in vitro. The combination of CXCL13, CXCR5, and $\mathrm{CD}^{+} \mathrm{T}$ cells was an independent predictor for survival. In addition, CXCL13 was associated with clusters of $\mathrm{CD} 20^{+} \mathrm{B}$ cells. CD20 ${ }^{+} \mathrm{B}$ cells predicted better patient survival in the presence of CXCL13. Histological evaluation highlighted colocalization of CXCL13 with tertiary lymphoid structures (TLSs). TLSs carried prognostic benefit only in the presence of CXCL13. CXCL13 in combination with anti-PD-1 therapy retarded tumor growth in a $\mathrm{CD}^{+} \mathrm{T}$-celldependent manner, resulting in increased infiltration of cytotoxic $\mathrm{CD}^{+} \mathrm{T}$ cells and $\mathrm{CXCR} 5^{+} \mathrm{CD} 8^{+} \mathrm{T}$ cells.

Conclusions These data define a critical role of CXCL13 in shaping antitumor microenvironment by facilitating the maintenance of $\mathrm{CXCR} 5^{+} \mathrm{CD}^{+} \mathrm{T}$ cells in TLSs and support a clinical investigation for a combination of CXCL13 and PD-1 blockade therapy in HGSC.

\section{BACKGROUND}

As the most prevalent histological subtype of epithelial ovarian cancer, high-grade serous ovarian cancer (HGSC) usually presents diffuse carcinogenesis in the advanced stage, and its 5-year survival rate is only $20 \%-30 \%{ }^{1}$ Immune checkpoint blockade targeting programmed cell death-1 (PD-1) and its ligand (PD-L1) has revolutionized contemporary treatment in a variety of tumors, but only a subset of patients with HGSC achieved encouraging clinical benefit. ${ }^{2}{ }^{3}$ Characterization of tumor immune microenvironment is critical for patient's stratification to guide optimal immune checkpoint interventions.

$\mathrm{CXCR}^{+} \mathrm{CD}^{+} \mathrm{T}$ cells, also known as follicular cytotoxic $\mathrm{T}$ cells (Tfc), are localized similarly to $\mathrm{CXCR}^{+}$follicular helper T (Tfh) cells in B-cell follicles. ${ }^{4}$ In the tumor microenvironment (TME), Tfc cells maintain selfrenewal capability during prolonged antigen exposure and might play an important role in sustaining antitumor immunity and responding to PD-1/PD-L1 blockade. ${ }^{5}{ }^{6} \mathrm{~A}$ high frequency of tumor-infiltrating Tfc cells is positively correlated with survival in lung, ${ }^{7}$ colorectal $^{4}$ and pancreatic ${ }^{8}$ cancers. Taken together, these findings suggest that tumorinfiltrating Tfc cells might be used as a potential biomarker to identify patients most likely to benefit from PD-1/PD-L1 blockade and predict the clinical outcomes in patients with HGSC.

B cells and tertiary lymphoid structures (TLSs) could be a potential biomarker and therapeutic target in response to immune checkpoint blockade therapy in patients with melanoma and renal cell carcinoma. ${ }^{9} 10$ Consistently, the presence of B cells in TLSs was associated with improved survival and a high response rate to $\mathrm{PD}-1$ blockade in patients with soft-tissue sarcoma. ${ }^{11}$ However, 
due to the variable functional status of TLSs, main contributors to induce favorable TLSs that augment antitumor efficacy remain unknown.

CXC-chemokine ligand 13 (CXCL13) exclusively binds to the chemokine receptor CXCR5, which is expressed on $\mathrm{B}$ cells, Tfh cells, and Tfc cells. ${ }^{56}$ CXCL13 helps to recruit specific B cells and CXCR5 ${ }^{+} \mathrm{T}$ cells to the site of chronic inflammation to coordinate both humoral and cellmediated adaptive immune responses. ${ }^{12}{ }^{13}$ CXCL13 plays a critical role in immune cell recruitment, activation, and adaptive immune response regulation, with its helper functions for B cells and cytotoxic T cells. ${ }^{14}$ CXCL13 also influences innate immunity by shaping the character and magnitude of inflammatory response. Consistently, CXCL13 expression has been confirmed to be strongly correlated with adaptive immune cell infiltration within colorectal cancer (CRC), as well as prolonged diseasefree survival in patients with CRC. ${ }^{15}$ Effects of CXCL13 on $\mathrm{CXCR}^{+} \mathrm{CD}^{+}{ }^{+}$-cell maintenance in the TME of HGSC and its prognostic significance remain elusive. Here, our purpose was to elucidate the prognostic significance of CXCL13 and its functional relevance to the maintenance of CXCR $5^{+} \mathrm{CD}^{+}{ }^{+} \mathrm{T}$ cells and immune contexture in HGSC.

\section{METHODS}

\section{Patients and specimens}

Tissue specimens from 185 patients with HGSC (training cohort; online supplemental table 1) who had undergone surgery between 2008 and 2015 were obtained from Gynecology and Obstetrics Hospital of Fudan University. All patients were followed up until April 2019. Tissue specimens from 79 patients with HGSC (validation cohort; online supplemental table 1) who had undergone surgery between May 2013 and August 2018 were obtained from Suzhou Municipal Hospital. All patients were followed up until March 2019. None of the patients had autoimmune disorder or a history of prior cancer. None of the patients was treated with chemotherapy, radiation, or any other antitumor medicines before tumor resection. Overall survival (OS) was calculated from the date of surgery to the date of death or last follow-up. Progression-free survival (PFS) was calculated from the date of surgery to the date of any type of progression diagnosis. Fresh tumor tissue samples were obtained from 36 patients with HGSC (online supplemental table 1) during surgery at the Department of Gynecology of our hospital, including 16 HGSC tissues used for ex vivo stimulation and immunofluorescence. For immunohistochemical and immunofluorescence studies, once the surgical specimens were obtained, all specimens were snap-frozen immediately in liquid nitrogen. Peripheral blood samples from 16 healthy donors and 46 patients with HGSC were collected from our hospital. For further research measurements, blood samples were collected to isolate plasma and stored in a freezer at $-80^{\circ} \mathrm{C}$ until further analysis. Normal ovarian tissues $(n=24)$ were obtained from Bank of Tumor Resources at our hospital. The clinical characteristics of all tissue samples from patients with HGSC are summarized in online supplemental table 1 . The number of samples used in each experiment is provided in online supplemental table 2.

\section{Tissue microarray preparation and immunohistochemistry}

Sections of formalin-fixed paraffin-embedded (FFPE) tissues were prepared and stained with H\&E. Two representative tumor areas per sample were confirmed and selected to generate tissue microarrays (TMAs). Tissue cores $(3 \mathrm{~mm}$ in diameter) were collected from the individual FFPE blocks and arranged in recipient paraffin blocks (TMA blocks). All TMA blocks were confirmed to contain suitable tumor lesions representing more than $50 \%$ of the core area based on H\&E staining.

Primary antibodies against the following antigens were used: CXCL13 (dilution 1:400; R\&D Systems), CD4 (dilution 1:200; Sigma-Aldrich), CD8 (dilution 1:200; Cell Signaling Technology), CD20 (dilution 1:800; Invitrogen), and CXCR5 (dilution 1:750; Sigma-Aldrich). Biotin-streptavidinHorseradish Peroxidase (HRP) detection systems (Origene) were applied for the following steps. Sections of lymph nodes that were previously shown to be positive for CXCL13 and CXCR5 were used as positive controls. Isotype antibody instead of primary antibody was used as a negative control (online supplemental figure $1 \mathrm{C}$ ).

\section{Immunohistochemical evaluation}

To avoid bias and subjective interpretation, immunohistochemistry (IHC) was evaluated independently and blindly by two investigators (JL and GZ) who were blinded to the clinical data. The sections with an interobserver variation of $>10 \%$ were reassessed using a double-headed light microscope to achieve consensus. Immunohistochemical staining of CXCL13 and CXCR5 was scored based on staining intensity on a scale of 0 to 3 (absent $=0$, weak $=1$, moderate $=2$, or strong $=3$ ), and a percentage of tumor cells was stained (range, $0 \%-100 \%$ ) using an algorithm developed for ImageJ (NIH), as previously described. ${ }^{16}$ Average CXCL13 or CXCR5 IHC score (range, $0-300)=\%$ positive staining $\times$ staining intensity $/ 5$ random high-power fields (HPFs). Intratumor staining and stroma CXCL13 staining were evaluated separately in all TMA cores determined by histological verification using H\&E (online supplemental figure 1B). The intratumor compartment was defined as the area encompassing all the cancer lesions, whereas the stroma compartment was the field along with the interface between the lesions and its neighborhood. Immunohistochemical staining of $\mathrm{CD}^{+}, \mathrm{CD}^{+}$, and $\mathrm{CD} 20^{+}$cellular infiltrates was counted based on the number of positively stained tumor infiltrated lymphocytes (TILs) by examining five representative HPFs under $200 \times$ magnification, and the cell counts were averaged. Optimal cut-offs for each protein were obtained using medium value-CXCL13: 115 stroma, 75 intratumor; CXCR5: 215; CD8: 6 cells/HPF; CD20: 7 cells/HPF. 
These cut-offs were used to stratify the tumors into low versus high for each protein.

\section{Preparation of single cells from HGSC tissues}

Fresh tissues were washed 3 times with cold phosphatebuffered saline (PBS) containing 1\% fetal bovine serum before being minced into small pieces. The specimens were collected in RPMI 1640 medium containing $1 \mathrm{mg} /$ $\mathrm{mL}$ collagenase IV and $10 \mathrm{mg} / \mathrm{mL}$ deoxyribonuclease I and mechanically dissociated using MACS Dissociator (Miltenyi Biotec). Dissociated cell suspensions were further incubated for 1 hour at $37^{\circ} \mathrm{C}$ under continuous rotation. The cell suspensions were then filtered through a $100 \mu \mathrm{m}$ cell strainer (BD), washed once with PBS, and resuspended in cell staining buffer.

\section{Ex vivo tumor stimulation assay}

Single-cell suspensions were cultured in 3D assay medium (RPMI 1640 medium prepared with 2\% Matrigel (BD) and supplemented with $100 \mathrm{IU} / \mathrm{mL}$ rhIL-2, $100 \mathrm{U} / \mathrm{mL}$ penicillin, $100 \mu \mathrm{g} / \mathrm{mL}$ streptomycin, and $10 \%$ fetal bovine serum). For stimulation assay, the medium was present with or without rhCXCL13 (R\&D Systems; $1 \mu \mathrm{g} / \mathrm{mL}$ ) for 48 hours at $37^{\circ} \mathrm{C}$ and $5 \% \mathrm{CO}_{2}$. Cells were collected by digestion with Liberase $\mathrm{DH}^{2}$ (Sigma-Aldrich) and subjected to flow cytometry analysis.

\section{Immunofluorescence}

For immunofluorescence staining, slides were incubated with goat anti-human CXCL13, mouse anti-human CD8, rabbit anti-human CXCR5, or mouse anti-human CD20. Alexa Fluor 488-conjugated, 594-conjugated, or 647-conjugated donkey anti-mouse/rabbit/goat secondary antibodies were used (Jackson ImmunoResearch). Cell nuclei were counterstained with 4',6-Diamidino-2-Phenylindole, Dihydrochloride (DAPI) (Sigma-Aldrich). Sections were sealed with Fluoromount Aqueous Mounting Medium (Sigma-Aldrich). Images were taken using confocal microscope (TCS SP8; Leica Microsystems). To measure the spatial relationship between CXCR $5^{+} \mathrm{CD} 8^{+}$or $\mathrm{CXCR}^{-} \mathrm{CD}^{+} \mathrm{T}$ cells and CXCL13, 16 samples from patients with HGSC were used for multiplex immunofluorescence, and at least five fields of view were taken for each sample using a 400-fold field of view. Leica LASX software was used to create a maximum projection image to be applied for subsequent analyses in ImageJ. The XY location of $\mathrm{CD} 8^{+}$objects and CXCL13 ${ }^{+}$ objects, and fluorescence colocalization of CXCR5 staining in $\mathrm{CD}^{+}$objects were determined in Image J. The distance from $\mathrm{CXCR} 5^{+} \mathrm{CD} 8^{+}$or $\mathrm{CXCR}^{-} \mathrm{CD}^{+} \mathrm{T}$ cells to the nearest CXCL13 ${ }^{+}$objects was calculated.

\section{Flow cytometry}

Single-cell suspensions were immunostained with a panel of fluorochrome-tagged monoclonal antibodies (online supplemental table 3). Red cells were lysed with an ammonium chloride solution, and samples were incubated with Live/Dead Fixable Dead Cell Staining Kit (ThermoFisher) before staining. Samples stained with isotype-matched antibodies were used as negative controls. For sample acquisition, a Beckman Coulter cytoflex flow cytometer with FACS CytExpert software was used (Beckman Coulter), and FlowJo software (Tree Star) was used for analyses.

\section{ELISA}

Serum concentrations of soluble CXCL13 protein were determined using a commercially available Quantikine kit (R\&D Systems) according to the manufacturer's instructions. The concentration of CXCL13 in the sera was interpolated from a standard curve, which was generated using the respective recombinant protein.

\section{TLS quantification}

TLSs were quantified using both H\&E and CD20 IHC staining. ${ }^{17}$ Structures were identified as aggregates of lymphocytes having histological features with analogous structures to lymphoid tissue with B cells (CD20) and T cells $(\mathrm{CD} 4, \mathrm{CD} 8)$ appearing in the tumor area.

\section{Chemotaxis assay}

Single cells from fresh collected HGSC tissues were resuspended in RPIM 1640 and placed at a concentration of $1 \times 10^{7}$ cells $/ \mathrm{mL}$ in the upper chamber of Transwell plates (Corning). For CXCR5 neutralizing group, cell suspension was incubated with $5 \mu \mathrm{g} / \mathrm{mL}$ anti-human CXCR5 (R\&D Systems) at $37^{\circ} \mathrm{C}$ for $30 \mathrm{~min}$. The lower chamber of Transwell plates contained RPIM 1640 with $1 \mu \mathrm{g} / \mathrm{mL}$ CXCL13 (R\&D Systems) to serve as a chemoattractant. Cells were allowed to migrate for 2 hours at $37^{\circ} \mathrm{C}$. Cells in the top and bottom of the transwell were harvested and analyzed using flow cytometry. Chemotaxis percentage was calculated as the migration percentage of the cell numbers of lower chamber to that of the total cell numbers and normalized to control migration.

\section{Animal experiments}

Female B6C3F1 mice were obtained from Charles River Laboratories (4-6 weeks old). All experiments were carried out in accordance with the guidelines for experimental animals at the Fudan University of China. OV2944-HM1 (HM-1) cells $\left(1 \times 10^{6}\right)$ were subcutaneously injected into the right flank using a $27 \mathrm{~g}$ needle. Tumor volume $\left(\mathrm{mm}^{3}\right)$ was measured every second day and calculated as (length $\times$ width $\left.^{2}\right) / 2$. rmCXCL13 ( $5 \mu$ g per mouse) was injected intraperitoneally on the day of tumor implantation and every other day thereafter until the end of the experiment. Mice were injected intraperitoneally with Invivo plus rat IgG2a isotype control $(100 \mu \mathrm{g}$, 2A3; BioXCell) or Invivo plus anti-mouse PD-1 (200 $\mathrm{gg}$, J43; BioXCell) or anti-mouse CD8 $\alpha$ (200 $\mu \mathrm{g}$, BE0061; BioXCell) every 3 days. For the combination therapy, mice were treated with anti-murine PD-1 with or without CXCL13 from 4 days after tumor implantation and readministered every 3 days for six maximum treatments. On the indicated days, tumors were harvested and either digested into single-cell suspension for flow cytometry analysis or formaldehyde-fixed for IHC of mouse CD8 (1:2000; 

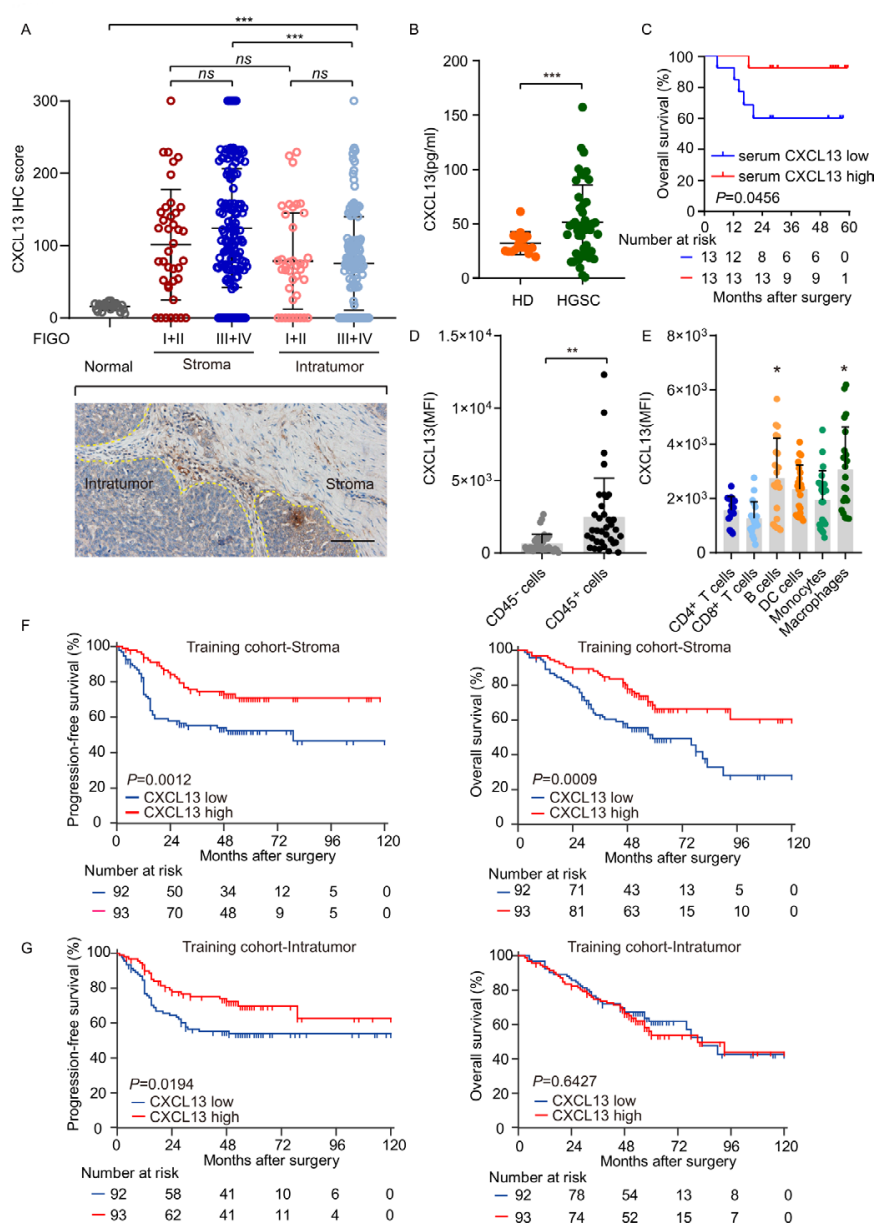

Figure $1 \mathrm{CXCL} 13$ is associated with improved survival in patients with HGSC. (A) H score of CXCL13 expression in normal ovarian tissue and stroma, and intratumor of HGSC tissues $(n=185)$. Bar $=100 \mu \mathrm{m}$. Results are expressed as mean $\pm S D$. (B) Concentration of CXCL13 of peripheral blood was compared between healthy donors $(n=16)$ and patients with HGSC ( $n=46$; Mann-Whitney $U$ test). (C) Kaplan-Meier survival curves for OS of patients with HGSC according to serum CXCL13 concentration $(n=26$; Gehan-Breslow-Wilcoxon test and $p$ values are shown). (D) CXCL13 expression of CD45 ${ }^{-}$or $\mathrm{CD}^{4} 5^{+}$cells was analyzed in HGSC tissues ( $n=36$; Mann-Whitney $U$ test). (E) The mean fluorescence intensity of CXCL13 on different subgroups of lymphocytes $(n=20$; one-way ANOVA with Bonferroni post hoc test; B cells: CD20 ${ }^{+}$DC: $C_{11} 1 b^{+} C D 11 c^{+}$, monocytes:

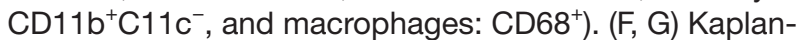
Meier survival curves for PFS and OS of patients with HGSC from the training cohort according to stroma or intratumor CXCL13 expression ( $n=185$; log-rank test and $p$ values are shown). ${ }^{*} p<0.05 ;{ }^{* \star} p<0.01 ;{ }^{* \star *} p<0.001 ; n s$, no significant difference. ANOVA, analysis of variance; CXCL13, CXC-chemokine ligand 13; HD, healthy donors; DC, dendritic cells; HGSC, high-grade serous ovarian cancer; IHC, immunohistochemistry; OS, overall survival; PFS, progression-free survival.
Abcam), CD20(1:800; Invitrogen), CD4 (1:2000; Abcam), and cleaved-caspase 3 (1:1500; CST).

\section{Statistical analyses}

Significant differences between two groups were determined by either Mann-Whitney $U$ test or unpaired t-test or paired t-test. Significant differences between three or more groups were determined by one-way analysis of varaince (ANOVA) or two-way ANOVA followed by multiple comparisons with the Bonferroni post hoc test. Simple correlations were summarized using the Pearson's correlation coefficient. Kaplan-Meier analysis and logrank test were used to analyze the OS and PFS of patients with HGSC . Univaraite and multivariate analyses were performed by Cox regression survival analyses (Enter for univariate and Backward and Forward methods for multivariate analyses). All statistical analyses were performed using GraphPad Prism V.8.0.0 (GraphPad Software) and MedCalc V.19.0.5 (MedCalc Software). Asterisks indicate the significance level of $p$ value: ${ }^{*} \mathrm{p}<0.05,{ }^{*} \mathrm{p}<0.01$, and $* * * \mathrm{p}<0.001$.

\section{RESULTS}

\section{Prognostic impact of CXCL13 in HGSC}

CXCL13 staining was significantly high in HGSC tissues and mainly located in stroma in specimens from patients with advanced-stage HGSC (figure 1A; online supplemental figure 1A-D). Compared with healthy donors $(n=16)$, CXCL13 concentrations in serum were significantly higher in patients with HGSC $(n=46$, (online supplemental table 1; figure 1B). After an average follow-up of 46.04 months, follow-up information was available on 26 patients, and higher CXCL13 concentration was indicative of prolonged OS ( $\mathrm{p}=0.0456$; figure $1 \mathrm{C}) . \mathrm{CD} 45^{+}$lymphocytes were the main source of CXCL13 in HGSC (figure 1D). Furthermore, $\mathrm{CD} 20^{+} \mathrm{B}$ cells and $\mathrm{CD} 68^{+}$macrophages represented the predominant source of CXCL13 (figure 1E). Patients with high levels of stroma CXCL13 staining exhibited significantly longer PFS and OS compared with their low CXCL13 counterparts (median PFS: >120 months vs 79 months; $\mathrm{p}=0.0012$; median OS: $>120$ months vs 59 months; $\mathrm{p}=0.0009$ ) (figure $1 \mathrm{~F}$ ). This phenomenon was more obvious in patients with advanced tumors (online supplemental figure 2A). We also identified a trend toward improved PFS (but not OS) for patients with HGSC with high levels of intratumoral CXCL13 (figure 1G). Univariate Cox analysis confirmed the prognostic impact for PFS of CXCL13 in both stroma $(\mathrm{p}=0.0018)$ and intratumor $(p=0.0223)$. However, CXCL13 as a continuous variable failed to reach a statistical significance in PFS and OS (online supplemental tables 4 and 5). To validate these findings, we evaluated the prognostic role of CXCL13 in an independent validation cohort. Stroma CXCL13 failed to predict survival in the validation cohort (online supplemental figure 1E). Also, patients in The Cancer Genome Atlas (TCGA) cohort were stratified by the median value of CXCL13 messenger RNA (mRNA) expression and 

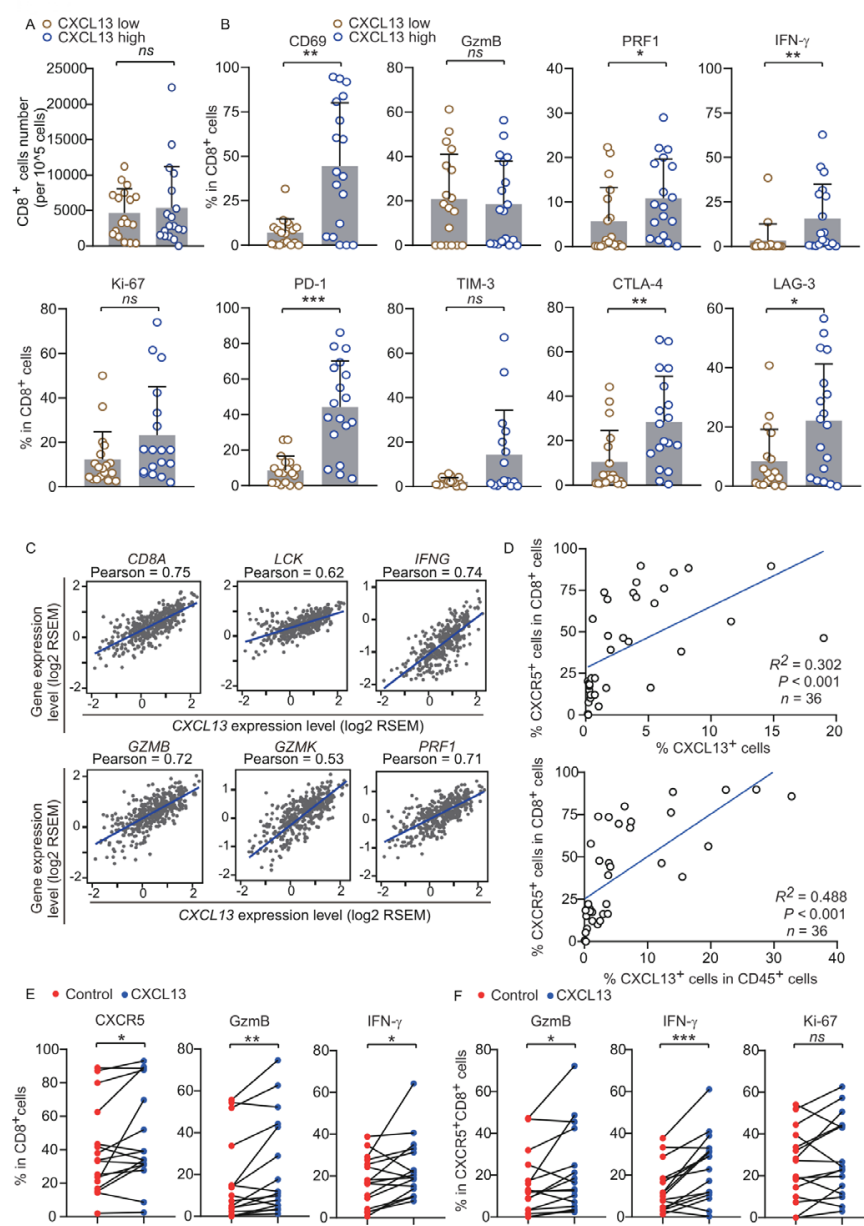

Figure 2 CXCL13 associates with antitumor immune microenvironment. (A) Difference in $\mathrm{CD}^{+} \mathrm{T}$-cell numbers per $10^{5}$ cells in HGSC tissues between CXCL13 low group and CXCL13 high group $(n=36)$. (B) Difference in effector cytokines (CD69, IFN- $\gamma$, GzmB, and PRF1), proliferation (Ki-67), and immune checkpoint molecule (PD-1, Tim-3, CTLA-4, LAG-3) expression on CD8 ${ }^{+} \mathrm{T}$ cells in HGSC tissues between CXCL13 low group and CXCL13 high group $(n=36)$. (C) Pearson's correlation of messenger RNA expression for CXCL13 with CD8A, LCK, IFNG, GZMB, GZMK, and PRF1 from TCGA. (D) Correlation analysis of $\mathrm{CXCR} 5^{+} \mathrm{CD} 8^{+}$ T-cell percentage with $\mathrm{CXCL} 13^{+}$cell percentage (upper) and $\mathrm{CXCL} 13^{+} \mathrm{CD} 45^{+}$cell percentage (lower) in HGSC tissues $(n=36)$. (E) Effects of rhCXCL13 on CD8 ${ }^{+} T$ cells from HGSC tissues ex vivo $(n=16)$. (F) Effects of rhCXCL13 on $\mathrm{CXCR}^{+} \mathrm{CD}^{+}{ }^{+}$T cells from HGSC tissues ex vivo $(n=16)$ (Mann-Whitney $U$ test in (A, B); Pearson's correlations in (C); linear regression in (D); paired t-test in $(E, F)$ ). Bar plots show mean $\pm S D$; ${ }^{*} p<0.05 ;{ }^{* *} p<0.01$; ${ }^{* * *} p<0.001$; ns, no significant difference. CXCL13, CXC-chemokine ligand 13; HGSC, high-grade serous ovarian cancer; IFN- $\gamma$, interferon- $\gamma$; PD-1, programmed cell death-1; PRF-1, perforin-1; RSEM, accurate quantification of gene and isoform expression from RNA-Seq data; TCGA, The Cancer Genome Atlas.

predicted better survival especially at advanced stage (online supplemental figure 2B,C).

CXCL13 associates with antitumor immune microenvironment $\mathrm{CD}^{+}$cytotoxic $\mathrm{T}$ cells are a key component of effective antitumor immunity, which can yield favorable prognosis in
HGSC. ${ }^{18}$ Thus, we explored the functional status of $\mathrm{CD}^{+} \mathrm{T}$ cells in 36 HGSC tumors, which was stratified by the median value of mean fluorescence intensity (MFI) of CXCL13 (online supplemental figure $4 \mathrm{~A}$ ). The counts of tumorinfiltrating $\mathrm{CD}^{+} \mathrm{T}$ cells showed no difference between the two groups (figure 2A; online supplemental figure $3 \mathrm{~A}$ ), whereas the elevation of CD69, interferon- $\gamma$ (IFN- $\gamma$ ), and perforin-1 (PRF1) expression in CD8 ${ }^{+}$T cells in the CXCL13 high group was confirmed (figure 2B; online supplemental figure 3A). The expression of immune checkpoint molecules in $\mathrm{CD}^{+} \mathrm{T}$ cells, including PD-1, cytotoxic T-lymphocyteassociated protein 4 (CTLA-4), and lymphocyte activation gene-3 (LAG-3), was also increased in the CXCL13 high group (figure 2B; online supplemental figure $3 \mathrm{~A}$ ). We found no obvious difference in the number of $\mathrm{CD} 4^{+} \mathrm{T}$ cells as well as effector molecule (CXCR5, GzmB, IFN- $\gamma$, and tumor necrosis factor- $\alpha(\mathrm{TNF}-\alpha)$ ) expression in $\mathrm{CD} 4^{+} \mathrm{T}$ cells between the two groups (online supplemental figure 4D,E). Further analyses revealed a positive correlation between CXCL13 mRNA and individual gene transcripts related to T-cell infiltration and antitumor immunity, including CD8A, $L C K, I F N G$, $G Z M B, G Z M K$, and PRF1 from TCGA (figure 2C). These data suggested that CXCL13 is associated with enhanced cytotoxic activity of $\mathrm{CD}^{+} \mathrm{T}$ cells. Given that CXCL13 is an exclusive ligand for CXCR5, we hypothesized that CXCR5 ${ }^{+} \mathrm{CD} 8^{+} \mathrm{T}$ cells may participate in CXCL13-mediated responses. To address this, we analyzed the correlation between these two factors. The percentage of $\mathrm{CXCL} 13^{+}$cells was positively associated with $\mathrm{CXCR} 5^{+} \mathrm{CD} 8^{+} \mathrm{T}$ cells in HGSC (figure 2D), and no correlation between CXCL13 and CXCR5 ${ }^{-} \mathrm{CD} 8^{+} \mathrm{T}$ cells was found (online supplemental figure $4 \mathrm{~B}$ ), while the abundance of $\mathrm{CXCR}^{+} \mathrm{CD}^{+} \mathrm{T}$ cells and $\mathrm{CXCR} 5{ }^{-} \mathrm{CD} 8^{+} \mathrm{T}$ cells exhibited similar trend (online supplemental figure 4C). To verify the effects of CXCL13 on CXCR5 ${ }^{+} \mathrm{CD} 8^{+} \mathrm{T}$ cells, we stimulated HGSC tissues using CXCL13 ex vivo. A significant increase in the percentage of CXCR $5^{+} \mathrm{CD} 8^{+} \mathrm{T}$ cells was observed after stimulation with CXCL13. CXCL13 also promoted the expression of GzmB and IFN- $\gamma$ in $\mathrm{CD}^{+} \mathrm{T}$ cells (figure 2E; online supplemental figure 2B). In addition, ex vivo CXCL13 stimulation significantly upregulated GzmB and IFN- $\gamma$ expression in $\mathrm{CXCR}^{+} \mathrm{CD}^{+} \mathrm{T}$ cells (figure $2 \mathrm{~F}$; online supplemental figure 2B), whereas no effect was observed on the proliferation or effector molecule (GzmB and IFN- $\gamma$ ) expression in $\mathrm{CXCR}^{-} \mathrm{CD}^{+} \mathrm{T}$ cells (online supplemental figure $4 \mathrm{~F}$ ). Effector molecule (CXCR5, IFN- $\gamma$, and TNF- $\alpha$ ) expression in $\mathrm{CD}^{+} \mathrm{T}$ cells was unaffected by CXCL13 stimulation (online supplemental figure 4G). These data were consistent with the hypothesis that $\mathrm{CXCR} 5{ }^{+} \mathrm{CD} 8^{+} \mathrm{T}$ cells contribute to CXCL13-mediated antitumor activity. Furthermore, TIM-3 expression was lower on $\mathrm{CXCR} 5^{+} \mathrm{CD} 8^{+} \mathrm{T}$ cells compared with CXCR5 ${ }^{-} \mathrm{CD}^{+} \mathrm{T}$ cells (online supplemental figure $4 \mathrm{H}$ ), but TIM-3 and PD-1 expression in CXCR $5^{+} \mathrm{CD} 4^{+}$ $T$ cells showed a conversely high level (online supplemental figure 4I). Taken together, these observations suggest that CXCL13 may influence antitumor immune responses by acting on $\mathrm{CXCR}^{+} \mathrm{CD} 8^{+} \mathrm{T}$ cells. 


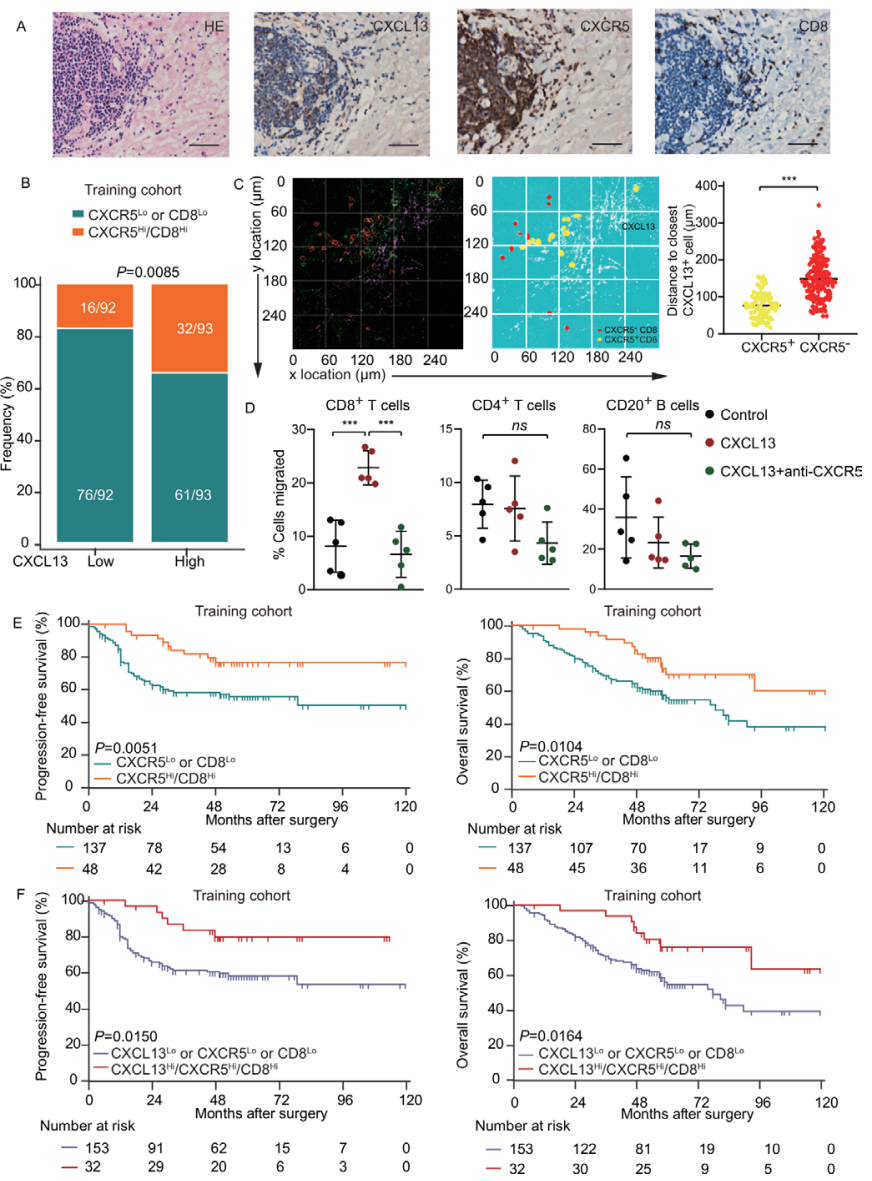

Figure 3 CXCL13-expressing and CXCR5-expressing $\mathrm{CD}^{+} \mathrm{T}$ cells colocalize and are associated with prolonged survival in HGSC. (A) Representative images of CXCR5, CD8, CXCL13 staining and H\&E staining in HGSC tissue. Bar $=50 \mu \mathrm{M}$, H\&E stain. (B) Frequency of CXCR5 ${ }^{\text {Lo }}$ or CD8 ${ }^{\text {Lo }}$ and $\mathrm{CXCR} 5^{\mathrm{Hi}} / \mathrm{CD} 8^{\mathrm{Hi}}$ patients from the training cohort was compared according to CXCL13 expression ( $n=185 ; \chi^{2}$ test and $p$ value is shown). (C) Spatial relationship map and distance from $\mathrm{CXCR} 5^{-}$and $\mathrm{CXCR} 5^{+} \mathrm{CD} 8^{+} \mathrm{T}$ cells to the closest $\mathrm{CXCL} 13^{+}$cell (unpaired t-test). (D) Migration of $\mathrm{CD}^{+}$ $\mathrm{T}$ cells, $\mathrm{CD}^{+} \mathrm{T}$ cells, and $\mathrm{CD} 2 \mathrm{O}^{+} \mathrm{B}$ cells from single-cell suspension from HGSC towards CXCL13 with or without CXCR5 neutralizing antibody $(n=5$, one-way ANOVA with Bonferroni post hoc test). (E) Kaplan-Meier survival curves for PFS (left) and OS (right) of patients with HGSC from the training cohort according to CXCR5-CD8 stratification ( $n=185$; log-rank test and $p$ values are shown). (F) KaplanMeier survival curves for PFS (left) and OS (right) of patients with HGSC from the training cohort according to CXCL13CXCR5-CD8 stratification ( $n=185$; log-rank test and $p$ values are shown). Bar plots show mean $\pm S D$; ${ }^{*} p<0.05$; ${ }^{* *} p<0.01$; ${ }^{* \star *} \mathrm{p}<0.001 ; n s$, no significant difference. ANOVA, analysis of variance; CXCL13, CXC-chemokine ligand 13; HGSC, high-grade serous ovarian cancer; OS, overall survival; PFS, progression-free survival.

\section{CXCL13-expressing and CXCR5-expressing CD8 ${ }^{+} \mathrm{T}$ cells} colocalize and are associated with prolonged survival in HGSC As CXCL13 contributes to activities of CXCR $5^{+} \mathrm{CD}^{+} \mathrm{T}$ cells in the TME, they would be expected to be located in close proximity. IHC in consecutive tissue sections showed that the distribution of CXCL13 was close to $\mathrm{CD} 8^{+}$cells, together with CXCR5 expression (figure 3A; online supplemental figure 5A). There was a strong correlation between CXCL13 and $\mathrm{CXCR}^{\mathrm{Hi}} / \mathrm{CD} 8^{\mathrm{Hi}}$ expression in both training and validation cohorts (figure 3B; online supplemental figure 5B). To further confirm this spatial correlation, we carried out three-color immunofluorescence with antibodies to CXCL13, CXCR5, and $\mathrm{CD} 8$. The distance between $\mathrm{CXCR} 5^{+} \mathrm{CD}^{+} \mathrm{T}$ cells and CXCL13 was significantly closer than CXCR5 ${ }^{-} \mathrm{CD}^{+} \mathrm{T}$ cells (figure 3C). Consistently, CXCL13 induced chemotaxis for $\mathrm{CD}^{+} \mathrm{T}$ cells, while its effect had been blocked by anti-CXCR5 neutralizing antibody (figure 3D). CXCR5 alone was not sufficient to distinguish survival of patients (online supplemental figure 5C,D). Confirming prior observations, ${ }^{18} \mathrm{CD}^{+}$ $\mathrm{T}$ cells had a positive impact on PFS of patients $(\mathrm{p}=0.018)$, but not on OS in the training or validation cohort (online supplemental figure $5 \mathrm{C}, \mathrm{D})$. Importantly, $\mathrm{CXCR} 5^{\mathrm{Hi}} / \mathrm{CD} 8^{\mathrm{Hi}}$ was associated with prolonged survival (median PFS and OS for $\mathrm{CXCR}^{\mathrm{Hi}} / \mathrm{CD} 8^{\mathrm{Hi}}$ were $>120$ months and $>120$ months) in the training cohort (figure 3E), which was confirmed in the validation cohort (online supplemental figure 5E). These data indicate that CXCR5 might potentially facilitate immune response of $\mathrm{CD}^{+} \mathrm{T}$ cells in HGSC. Next, we investigated the prognostic value of combined CXCL13, CXCR5, and CD8 and revealed that $\mathrm{CXCL} 13^{\mathrm{Hi}} / \mathrm{CXCR} 5^{\mathrm{Hi}} / \mathrm{CD} 8^{\mathrm{Hi}}$ predicted superior survival compared with their counterpart in both training and validation cohorts (figure 3F; online supplemental figure $5 \mathrm{~F}$ ). Multivariate analysis demonstrated that CXCL13 ${ }^{\mathrm{Hi}} / \mathrm{CXCR}^{\mathrm{Hi}} / \mathrm{CD} 8^{\mathrm{Hi}}$ represented an independent prognostic predictor in the training cohort (table 1). All the above findings indicate that the concomitant assessment of CXCL13, CXCR5, and CD8 ${ }^{+} \mathrm{T}$ cells in the tumor of patients with HGSC conveys robust prognostic information.

\section{CXCL13 correlates with conglomerated $\mathrm{CD}^{+}{ }^{+} \mathrm{B}$ cells and prolongs survival}

CXCL13 can recruit not only CXCR $5^{+} \mathrm{CD} 8^{+} \mathrm{T}$ cells but also $\mathrm{CD}^{2} 0^{+} \mathrm{B}$ cells and has an auxiliary effect on its functions. ${ }^{14}$ Thus, we assumed that CXCL13 may correlate with B cells in the tumor of HGSC. We observed CD20 ${ }^{+} \mathrm{B}$ cells diffused or clustered in the stroma (figure 4A). Contrary to expectation, there was no correlation between CXCL13 and CD20 ${ }^{+} \mathrm{B}$ cells. Nevertheless, the conglomerate of $\mathrm{CD} 20^{+} \mathrm{B}$-cell density increased with high CXCL13 level (figure 4B), indicating that CXCL13 may contribute to CD20 $0^{+}$B-cell agglomeration in TME of HGSC. The colocalization between CXCL13 and conglomerated $\mathrm{CD} 20^{+} \mathrm{B}$ cells was confirmed by dualcolor immunofluorescence (figure 4C). The prognostic significance of $\mathrm{CD} 20^{+} \mathrm{B}$ cells remains inconsistent, ${ }^{190}$ and no prognostic significance of $\mathrm{CD} 20^{+} \mathrm{B}$ cells was observed in the training cohort (figure 4D). As the presence of both $\mathrm{CD}^{+} 0^{+}$and $\mathrm{CD}^{+}$TILs correlated with improved survival in patients with $\mathrm{HGSC},{ }^{21}$ we assessed PFS and OS on stratifying patients into two subsets $\left(\mathrm{CXCL} 13^{\mathrm{Hi}} / \mathrm{CD} 20^{\mathrm{Hi}}\right.$, CXCL1 $13^{\mathrm{LO}}$ or $\mathrm{CD} 20^{\mathrm{Lo}}$ ). $\mathrm{CXCL} 3^{\mathrm{Hi}} / \mathrm{CD} 20^{\mathrm{Hi}}$ exhibited better OS (median $>120$ months) than counterparts of CXCL1 $3^{\mathrm{Lo}}$ or $\mathrm{CD} 20^{\mathrm{Lo}}$ (median=78months, $\mathrm{p}=0.0354)$. Meanwhile, CXCL13 ${ }^{\mathrm{Hi}}$ / $\mathrm{CD} 20^{\mathrm{Hi}}$ patients exhibited better PFS ( $\left.\mathrm{p}=0.0253\right)$ (figure $4 \mathrm{E}$ ). 
Table 1 Multivariable analyses of PFS and OS of patients with HGSC in the training cohort

\begin{tabular}{|c|c|c|c|c|c|c|}
\hline \multirow[b]{2}{*}{ Variables } & \multicolumn{3}{|c|}{ PFS } & \multicolumn{3}{|c|}{ os } \\
\hline & $P$ value & HR & $95 \% \mathrm{Cl}$ & $P$ value & HR & $95 \% \mathrm{Cl}$ \\
\hline Age at diagnosis & 0.1441 & 0.9764 & 0.9455 to 1.0082 & 0.8567 & 1.0032 & 0.9687 to 1.0389 \\
\hline$>20$ vs $\leq 20$ & 0.7875 & 0.8862 & 0.3682 to 2.1331 & 0.4850 & 1.4645 & 0.5019 to 4.2732 \\
\hline \multicolumn{7}{|l|}{ CA125 (mg/L) } \\
\hline III+IVvs I+II & 0.0091 & 4.8453 & 1.4790 to 15.8732 & 0.0211 & 5.4391 & 1.2889 to 22.9533 \\
\hline \multicolumn{7}{|l|}{ Tumor residual (cm) } \\
\hline$>1$ vs $\leq 1$ & 0.0978 & 0.3663 & 0.1115 to 1.2028 & 0.0841 & 1.9999 & 0.9110 to 4.3905 \\
\hline \multicolumn{7}{|l|}{ Primary therapy response } \\
\hline
\end{tabular}

$\mathrm{P}<0.05$ marked in bold font shows statistical significance.

CA125, cancer antigen 125; CXCL13, CXC-chemokine ligand 13; FIGO, Federation of Gynecology and Obstetrics ; HGSC, high-grade serous ovarian cancer; OS, overall survival; PFS, progression-free survival.

Collectively, these results suggest that CXCL13 may contribute to the survival benefit of $\mathrm{CD} 20^{+} \mathrm{B}$ cells by promoting its agglomeration in the TME.

\section{CXCL13 localizes in the context of TLSs and prolongs survival}

In our previous results, we observed colocalization between CXCL13 and CXCR $5^{+} \mathrm{CD}^{+}$T cells, as well as CD20 ${ }^{+}$B-cell clusters in the HGSC TME, which have been regarded as markers of TLS formation. ${ }^{10}$ We evaluated the presence of TLSs in the HGSC and found 50 of 185 specimens contained TLSs $(27 \%)$ (figure 5A; online supplemental figure 6A), consistent with the previous study. ${ }^{22}$ To our surprise, there was no correlation between CXCL13 and TLSs (figure 5B), and TLSs showed no significant correlation with clinical outcomes in patients with HGSC (online supplemental figure 6B). Intriguingly, we observed a correlation between CXCL13 and prolonged OS exclusively in patients with HGSC who presented with TLSs, but not counterparts without TLSs (figure 5C). These data imply that CXCL13 may rely on the TLSs to exert antitumor function in HGSC. Moreover, immunofluorescence staining of two known TLS markers (CXCR5 and CXCL13), in combination with $\mathrm{CD} 8$ and $\mathrm{CD} 20$, supported the notion that CXCL13 promoted CXCR5 ${ }^{+} \mathrm{CD}^{+}$T-cell recruitment to TLSs (figure 5D). Statistics confirmed the correlation between CXCL13 and CXCR5 $5^{\mathrm{Hi}} / \mathrm{CD}^{\mathrm{Hi}}$ in patients with HGSC with TLSs (figure 5E). These data suggest that the combination of CXCL13 and TLSs probably represents an immune activation status associated with $\mathrm{CXCR} 5^{+} \mathrm{CD} 8^{+} \mathrm{T}$ cells for patients with HGSC.

\section{CXCL13 enhances the response of anti-PD-1 therapy in subcutaneous ovarian cancer mouse model}

As $\mathrm{CXCR}^{+} \mathrm{CD}^{+} \mathrm{T}$ cell was reported to be the main responding factor during immune checkpoint blockade, ${ }^{6}$ we explored the effect of CXCL13 on the response of checkpoint blockade therapy in vivo. Treatment of subcutaneous ovarian cancer mice with the combination of CXCL13 and anti-PD-1 significantly retarded tumor growth (figure 6A,B), which could probably derive from the increased $\mathrm{CD}^{+} \mathrm{T}$-cell infiltration in mouse tumors (figure 6C; online supplemental figure 7A). The percentages of CD44, IFN- $\gamma$, and interleukin 2 (IL-2) in $\mathrm{CD}^{+} \mathrm{T}$ cells were significantly higher in the CXCL13 treatment group (figure 6D; online supplemental figure $7 \mathrm{~B}$ ). In the meanwhile, the combination treatment promoted the expression of CD44 and IL-2 compared with anti-PD-1 treatment alone (figure 6D; online supplemental figure $7 \mathrm{~B}$ ). Consistent with the results of in vitro experiments, CXCL13 alone or combined with anti-PD-1 increased the proportion of $\mathrm{CXCR}^{+} \mathrm{CD}^{+} \mathrm{T}$ cells in the spleen, tumor-associated lymph nodes, and tumors (figure 6E; online supplemental figure 7C). The Ki-67 and T-bet expression in CXCR5 ${ }^{+} \mathrm{CD} 8^{+}$ $\mathrm{T}$ cells was significantly enhanced by combination treatment (figure 6F, online supplemental figure 7D). On combination treatment, the increased counts of $\mathrm{CD} 8^{+}$TILs and the expression of cleaved-caspase 3 were confirmed by IHC (online supplemental figure $7 \mathrm{E}$ ). To verify the critical role of $\mathrm{CD}^{+} \mathrm{T}$ cells in the antitumor effects during the combination therapy, $\mathrm{CD}^{+} \mathrm{T}$ cells were eliminated by neutralizing antibodies (figure 6G). The antitumor effect of CXCL13 plus anti-PD1 therapy had been reversed by $\mathrm{CD}^{+}$T-cell depletion (figure $6 \mathrm{H}$ and $\mathrm{I}$ ). These data suggest that CXCL13 may potentiate response of anti-PD-1 therapy through expansion and activation of $\mathrm{CXCR}^{+} \mathrm{CD}^{+} \mathrm{T}$ cells.

\section{DISCUSSION}

This work provides new insights into the potential role of CXCL13 in the maintenance of $\mathrm{CXCR}^{+} \mathrm{CD}^{+} \mathrm{T}$ cells that contribute to immune checkpoint blockade therapy in 

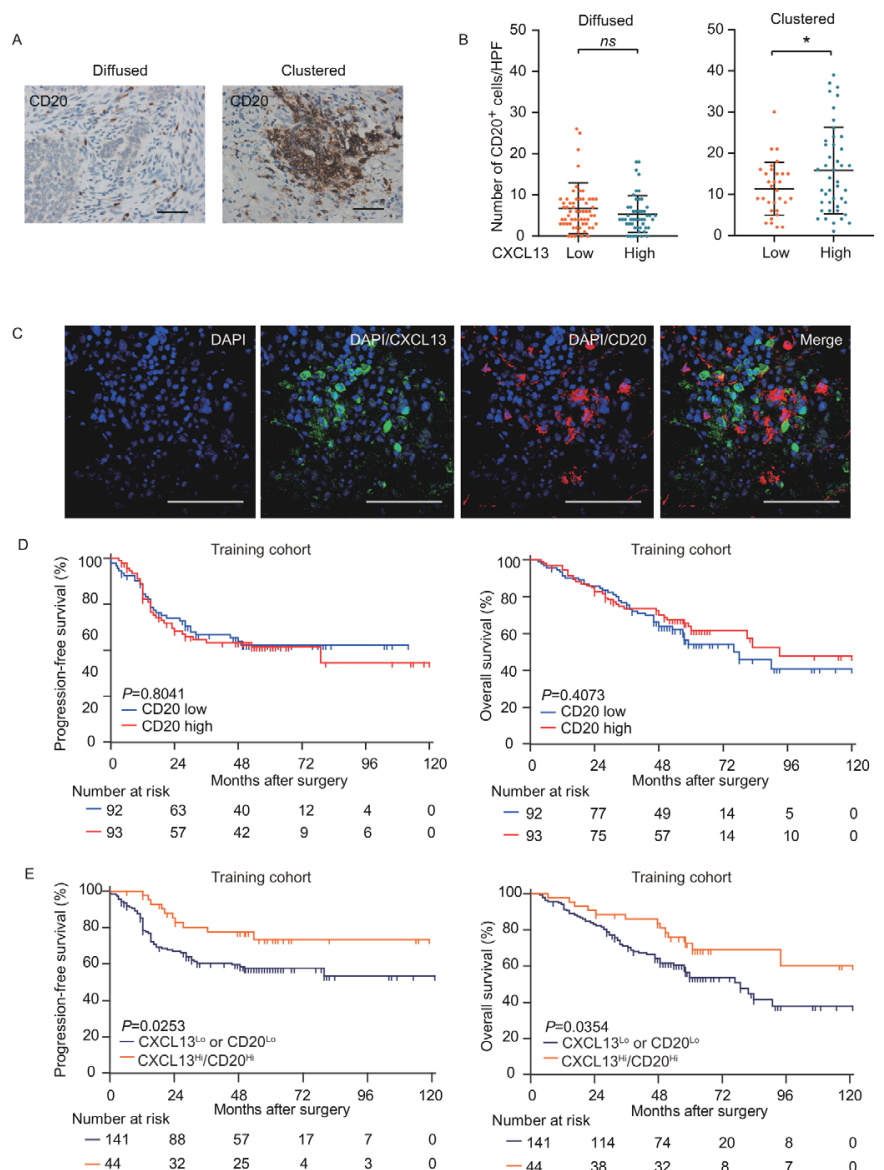

Figure 4 CXCL13 correlates with conglomerated CD20 ${ }^{+}$ $B$ cells and prolongs survival. (A) Representative images of $\mathrm{CD}^{2} \mathrm{O}^{+} \mathrm{B}$ cells in HGSC. Diffused (left) and clustered (right). Bar $=50 \mu \mathrm{M}$. (B) Numbers of CD20 ${ }^{+}$B cells were compared between patients with low and high CXCL13 expression. Diffused ( $n=107$, left) and clustered ( $n=78$, right) (MannWhitney U test). (C) Representative immunofluorescence staining of HGSC. The sample was stained for CXCL13 (magenta), CXCR5 (red), CD8 (green), and DAPI (blue). Bar $=50 \mu \mathrm{M}$. (D) Kaplan-Meier survival curves for PFS (left) and OS (right) of patients with HGSC from the training cohort according to $C D 20^{+} B$-cell density $(n=185$; log-rank test and $p$ values are shown). (E) Kaplan-Meier survival curves for PFS (left) and OS (right) of patients with HGSC from the training cohort according to CXCL13-CD20 stratification. $(n=185$; log-rank test and $p$ values are shown). CXCL13, CXCchemokine ligand 13; DAPI, 4',6-Diamidino-2-Phenylindole, Dihydrochloride; HGSC, high-grade serous ovarian cancer; OS, overall survival; PFS, progression-free survival.

HGSC. Elevated CXCL13 expression in tumors suggested a more immunoactive microenvironment and tended to prolong patient's survival. CXCL13 was located adjacent to $\mathrm{CXCR}^{+} \mathrm{CD}^{+} \mathrm{T}$ cells in vivo and promoted recruitment and activation of $\mathrm{CXCR}^{+} \mathrm{CD}^{+} \mathrm{T}$ cells in vitro. Combination of CXCL13, CD8, and CXCR5 was confirmed as an independent prognostic factor for OS and PFS in patients with HGSC. Combining CXCL13 with PD-1 blockade therapy enhanced antitumor response and retarded tumor growth, which was
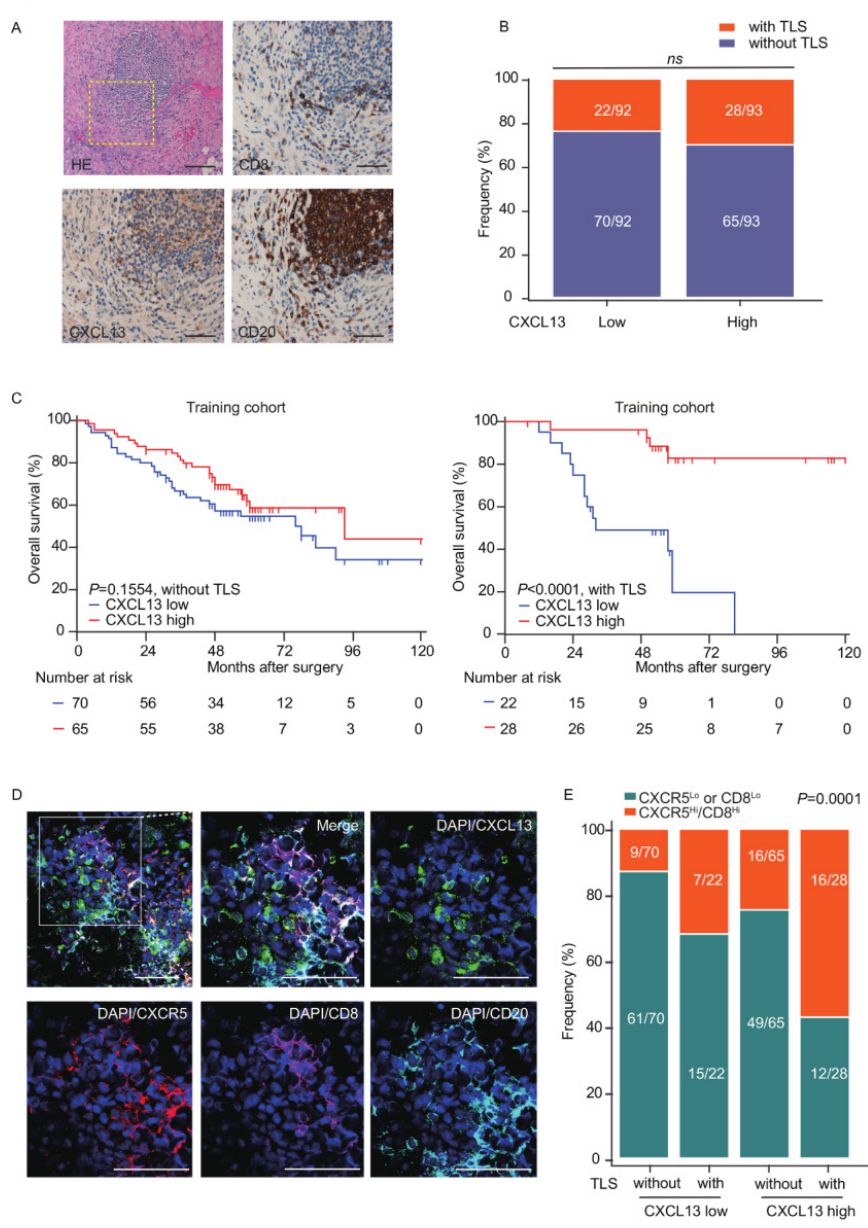

Figure 5 CXCL13 localizes in the context of TLSs and prolongs survival. (A) Representative images of immunostaining with H\&E, CD20, CD8, and CXCL13 in HGSC. Bar $=50 \mu \mathrm{M}$. (B) The frequency of patients with or without TLSs was compared according to CXCL13 expression ( $n=185, \chi 2$ test). (C) Kaplan-Meier survival curves for OS of patients with HGSC from the training cohort without ( $n=135$, left) or with TLSs ( $n=50$, right) according to CXCL13 expression (log-rank test and $p$ values are shown). (D) Representative images of immunofluorescence staining of HGSC. The sample was stained for CXCL13 (green), CXCR5 (red), CD8 (magenta), CD20 (cyan-blue) and DAPI (blue). Bar $=50 \mu \mathrm{M}$. (E) The frequency of $C X C R 5^{\text {Lo }}$ or CD8 ${ }^{\text {Lo }}$ and $\mathrm{CXCR} 5^{\mathrm{Hi}} / \mathrm{CD} 8^{\mathrm{Hi}}$ patients from the training cohort was compared according to the TLS-CXCL13 group. ( $n=185$; $\chi^{2}$ test and $p$ value is shown). CXCL13, CXC-chemokine ligand 13; HGSC, high-grade serous ovarian cancer; OS, overall survival; DAPI, 4',6-Diamidino-2-Phenylindole, Dihydrochloride; TLSs, tertiary lymphatic structures.

abolished on depletion of $\mathrm{CD}^{+} \mathrm{T}$ cells (online supplemental figure 8).

Recent studies reported that follicular dendritic cells and Tfh cells were major sources of CXCL13. ${ }^{13} 23$ In addition, $\mathrm{CD}^{+}$TIL was a potent producer of CXCL13 in human melanoma, non-small cell lung cancer, breast cancer, and hepatocellular carcinoma. ${ }^{24-27}$ In rheumatoid arthritis and ulcerative colitis, most cells that express CXCL13 were of the macrophage lineage, ${ }^{28}$ whereas in chronic obstructive pulmonary 

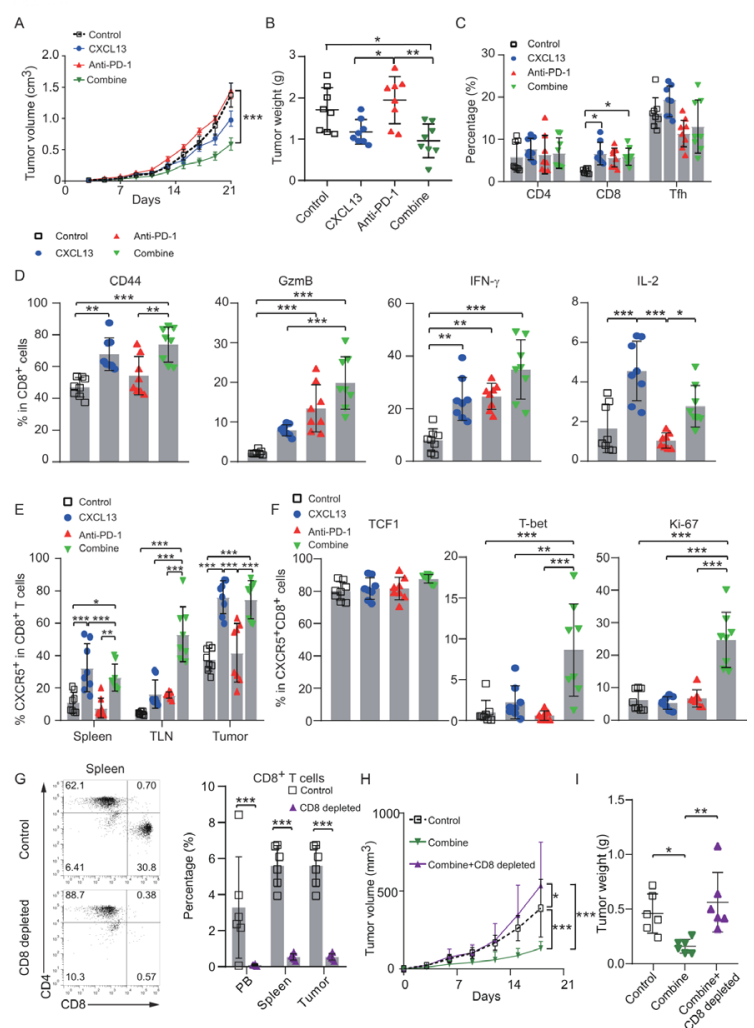

Figure 6 CXCL13 enhances response of anti-PD-1 therapy in subcutaneous ovarian cancer mouse model. (A) Tumor growth curves of subcutaneous tumor model treated with CXCL13 or anti-PD-1 or combination of CXCL13 and antiPD-1. Dotted lines indicate the time point at which tumor sizes were compared between control and treatment groups ( $n=8$ per group). (B) Tumor weights of subcutaneous tumor among the indicated four groups ( $n=8$ per group). (C) Percentage of $\mathrm{CD}^{+}{ }^{+} \mathrm{T}$ cells, CD4 ${ }^{+} \mathrm{T}$ cells and Tfh in TILs from subcutaneous tumor among the indicated four groups ( $n=8$ per group). (D) Percentage of effector cytokines (CD44, GzmB, IFN- $\gamma$, and IL-2) in CD8 ${ }^{+} \mathrm{T}$ cells from subcutaneous tumor among the indicated four groups ( $n=8$ per group). (E) Percentage of $\mathrm{CXCR} 5^{+} \mathrm{CD} 8^{+} \mathrm{T}$ cells from spleen, TLN, and subcutaneous tumor among the indicated four groups $(n=8$ per group). (F) Percentage of transcription factors (TCF1, T-bet) and $\mathrm{Ki}-67$ in $\mathrm{CXCR} 5^{+} \mathrm{CD} 8^{+} \mathrm{T}$ cells from subcutaneous tumor among the indicated four groups ( $n=8$ per group). $(G)$ Percentage of $\mathrm{CD}^{+} \mathrm{T}$-cell percentage in mouse spleens from control and $\mathrm{CD}^{+}$T-cell-depleted groups ( $\mathrm{n}=6$ per group). $(\mathrm{H})$ Tumor growth curves of subcutaneous tumor model treated by combination therapy with or without $\mathrm{CD} 8^{+} \mathrm{T}$-cell depletion. Dotted lines indicate the time point at which tumor sizes were compared between control and treatment groups $(n=6$ per group). (I) Tumor weights of subcutaneous tumor model treated by combination therapy with or without $\mathrm{CD}^{+} \mathrm{T}$-cell depletion (two-way ANOVA with Bonferroni post hoc test in $(A, H)$; one-way ANOVA with Bonferroni post hoc test in $(B-F)$ and (I); paired t-test in (G)). Bar plots show mean $\pm S D$; ${ }^{*} \mathrm{p}<0.05$; ${ }^{* *} \mathrm{p}<0.01$; ${ }^{* \star *} \mathrm{p}<0.001$; ns, no significant difference. ANOVA, analysis of variance; CXCL13, CXC-chemokine ligand 13; HGSC, high-grade serous ovarian cancer; IFN- $\gamma$, interferon- $\gamma$; IL-2, interleukin 2; OS, overall survival; PD-1, programmed cell death-1; Tfh, follicular helper T cells; TILs, tumor infiltrated lymphocytes; TLN, tumor-associated lymph nodes. disease, they were B cells. ${ }^{29}$ Consistently, our results demonstrated that $\mathrm{B}$ cells and macrophages are the main source of CXCL13 in HGSC.

CXCL13 acts through its cognate receptor, CXCR5, to recruit lymphocytes to B-cell zones of secondary lymphoid tissues. Normally, mature B cells and a subset of memory $\mathrm{T}$ cells expressed CXCR5 and migrated in response to CXCL13 ${ }^{30}$ Our results revealed that CXCR5 in $\mathrm{CD} 8{ }^{+} \mathrm{T}$ cells is strongly associated with prolonged survival. As CXCR5expressing B cells were not associated with outcomes in the HGSC, this may interfere with the prognostic value of CXCR5 alone.

CXCL13 induced chemotaxis of B cells and upregulation of B-cell lymphotoxin- $\alpha 1 \beta 2$ to drive a positive feedback loop that is important in germinal center (GC) development and homeostasis. ${ }^{31}$ In addition, CXCL13 orchestrated B-cell clustering, lymphoid aggregation, and antibody production in TLSs. ${ }^{32}$ CXCL13-producing CXCR5 ${ }^{+}$Tfh cells were primarily located in TLSs and distinguished extensive immune infiltrates in breast cancer. ${ }^{13}$ CXCL13-producing CXCR5 $5^{-} \mathrm{CD} 4^{+}$ Tfh cells (TFHX13) potentially triggered TLS formation and generated GC B-cell responses at the breast cancer site. ${ }^{27}$

Three subsets of $\mathrm{CXCR}^{+} \mathrm{CD} 8^{+} \mathrm{T}$ cells have been defined by immune context as progenitors of exhausted $\mathrm{CD} 8^{+} \mathrm{T}$ cells, ${ }^{5}$ regulatory $\mathrm{CD}^{+} \mathrm{T}$ cells, ${ }^{33}$ and follicular helper $\mathrm{CD}^{+} \mathrm{T}$ cells. ${ }^{34}$ In hepatitis B virus-associated hepatocellular carcinoma, $\mathrm{CXCR}^{+} \mathrm{CD}^{+} \mathrm{T}$ cells could induce tumor cell death more effectively than CXCR5 5 counterparts. ${ }^{35}$ In pancreatic cancer, $\mathrm{CXCR}^{+} \mathrm{CD}^{+} \mathrm{T}$ cells represented a promising subset of $\mathrm{CD} 8^{+}$ T cells and could respond to anti-PD1/anti-TIM3 blockade. ${ }^{8}$ In $\mathrm{CRC}, \mathrm{CXCR} 5^{+} \mathrm{CD}^{+} \mathrm{T}$ cells potentially contributed to antitumor immunity and were highly activated in tumordraining lymph nodes to achieve prognostic benefit. ${ }^{46}$ In our results, $\mathrm{CXCR} 5^{+} \mathrm{CD}^{+} \mathrm{T}$ cells demonstrated higher IFN- $\gamma$ and granzyme $\mathrm{B}$ expression and a more potent proliferation capability following CXCL13 exposure ex vivo. CXCL13 plus anti-PD1 blockade similarly promoted the proliferation of CXCR $5^{+} \mathrm{CD}^{+} \mathrm{T}$ cells in tumor-bearing mice.

The differentiation of $\mathrm{CXCR}^{+} \mathrm{CD} 8^{+} \mathrm{T}$ cells required the transcription factors TCF1, Bcl6, and E2A but was inhibited by the transcription regulators Blimp1, Id2, Id3, Irf4, Runx3, and STAT4. ${ }^{34}$ 37-40 However, less is known about the specific cytokines that participate in the maintenance of these cells. Interleukin 12 (IL-12) downregulated the expression of TCF1 in $\mathrm{CD}^{+} \mathrm{T}$ cells via STAT4 signaling, suggesting IL-12 may suppress CXCR $5^{+} \mathrm{CD} 8^{+}$T-cell differentiation. ${ }^{40}$ Cell-intrinsic type I interferon (IFN-I) signaling suppressed $\mathrm{TCF}^{\text {high }}$ progenitor-like $\mathrm{CD} 8^{+} \mathrm{T}$-cell differentiation, but blockade of IFN-I receptor led to $\mathrm{CXCR} 5^{+} \mathrm{CD}^{+}$ T-cell expansion in an interleukin 27-dependent and STAT1-dependent manner. ${ }^{41}{ }^{42}$ Our data confirmed the positive correlation between CXCL13 and $\mathrm{CXCR}^{+} \mathrm{CD}^{+}$ $\mathrm{T}$ cells. CXCL13 stimulated activation and expansion of $\mathrm{CXCR}^{+} \mathrm{CD}^{+} \mathrm{T}$ cells in HGSC tumors ex vivo and promoted recruitment of $\mathrm{CXCR} 5^{+} \mathrm{CD} 8^{+} \mathrm{T}$ cells in vitro. Still the detailed molecular mechanism underlying CXCL13driven expansion of $\mathrm{CXCR} 5^{+} \mathrm{CD} 8^{+} \mathrm{T}$ cells needs further investigation. 
Compared with the circulating population, tumorinfiltrating $\mathrm{CXCR}^{+} \mathrm{CD}^{+} \mathrm{T}$ cells expressed higher levels of PD-1 and TIM-3. On PD-1 and TIM-3 blockade, the function of $\mathrm{CXCR}^{+} \mathrm{CD} 8^{+} \mathrm{T}$ cells was further improved. ${ }^{8}$ In muscle-invasive bladder cancer, $\mathrm{CXCR} 5^{+} \mathrm{CD}^{+} \mathrm{T}$ cells expressed elevated PD-1, LAG-3, and CTLA-4 and reduced TIM-3 compared with CXCR5 ${ }^{-} \mathrm{CD} 8^{+}$T-cell counterparts. ${ }^{43}$ $\mathrm{TCF}^{+} \mathrm{CD}^{+}{ }^{+} \mathrm{T}$ cells with PD-1 and LAG-3 expression were crucial for the T-cell expansion that occurred in response to inhibitory receptor blockade during chronic infection. ${ }^{37}$ Our results indicated that CXCR5 ${ }^{+} \mathrm{CD}^{+} \mathrm{T}$ cells expressed lower TIM-3 expression compared with CXCR5 ${ }^{-} \mathrm{CD}^{+}{ }^{+}$T-cell counterparts. CXCR5 ${ }^{+} \mathrm{CD} 8^{+} \mathrm{T}$ cells produced more effector molecules (such as GzmB and IFN- $\gamma$ ) on CXCL13 incubation in HGSC tissues, but CXCR5 ${ }^{-} \mathrm{CD}^{+} \mathrm{T}$ cells remained unresponsive.

During HIV and Epstein-Barr virus infection, $\mathrm{CXCR}^{+} \mathrm{CD}^{+} \mathrm{T}$ cells selectively entered B-cell follicles and eradicated the infected $\mathrm{CD} 4^{+} \mathrm{Tfh}$ cells and $\mathrm{B}$ cells. $^{34}{ }^{44}$ In rheumatoid synovitis, perifollicular CD8 ${ }^{+} \mathrm{T}$ cells facilitated the structural function of GC in ectopic lymphoid follicles. ${ }^{45}$ The association of B-cell-rich TLSs and survival and anti-PD1 immunotherapy response in soft-tissue sarcoma and melanoma has been recently established. ${ }^{911}$ In addition, co-occurrence of tumorassociated $\mathrm{CD} 8^{+} \mathrm{T}$ cells and $\mathrm{CD} 20^{+} \mathrm{B}$ cells is associated with improved survival in melanomas. Furthermore, B-cellrich tumors were accompanied by increased numbers of $\mathrm{TCF}^{+}$-naïve and/or memory T cells. ${ }^{10}$ Similarly, immunofluorescence staining of CXCL13, CXCR5, and CD8 in combination with CD20 displayed the formation of TLSs in HGSC. CXCR5 ${ }^{+} \mathrm{CD}^{+}{ }^{+} \mathrm{T}$ cells were adjacent to CXCL13 and B-cell follicles, suggesting a clue that $\mathrm{CXCR} 5^{+} \mathrm{CD}^{+} \mathrm{T}$ cells may take part in the formation of lymphoid follicles. Our results indicate that the combination of CXCL13 and TLSs is associated with prolonged OS. CXCL13 potentiated PD-1 blockade therapy against tumors, implying its potential utility as a biomarker for stratification and response to immune checkpoint blockade therapy.

Our study has several limitations. First, the number of patients in the validation cohort was relatively small. Second, this study included patients with HGSC of all stages from three cohorts (training, validation, and TCGA), which resulted in a large but clinically heterogeneous retrospective study cohort. Third, CXCL13 staining is heterogeneous in some TMA cores, and the predominant pattern was taken into account for scoring. Still, the TMA method could provide meaningful information when used in a large cohort. Fourth, the molecular mechanisms by which CXCL13 induced maintenance of $\mathrm{CXCR}^{+} \mathrm{CD}^{+} \mathrm{T}$ cells in HGSC need to be further explored. Considering the above-mentioned limitations, a multicenter prospective cohort study should be taken.
$\mathrm{CXCR}^{+} \mathrm{CD} 8^{+} \mathrm{T}$ cells, and its effect could be dependent on immune contexture shaping including TLSs. Combined CXCR5-CD8-CXCL13 IHC score represents a potential biomarker for stratification of clinical outcomes in patients with HGSC. Our findings also provide a perspective on CXCL13 promoting the response of HGSC to PD-1 blockade. Accordingly, CXCL13 and CXCR5 ${ }^{+} \mathrm{CD} 8^{+}$ $\mathrm{T}$ cells should be considered as a potential prognosticator or response biomarker for immune checkpoint blockade therapy.

Acknowledgements We thank Dr Jing Zhao (Department of pathology, Obstetrics and Gynecology Hospital of Fudan University, Shanghai, China) for her excellent pathological technology help and Dr Hongbo Zhao (Bank of Tumor Resources, Obstetrics and Gynecology Hospital of Fudan University, Shanghai, China) for her help.

Contributors HL performed study concept and design; acquisition, analysis, and interpretation of data; and study supervision. CX obtained funding and study supervision. MY, JL, and GZ performed acquisition, analysis, and interpretation of data and statistical analysis. YW, MH, and QX provided technical and material support. All authors read and approved the final manuscript.

Funding This study was funded by grants from National Key Research and Development Program of China (2016YFC1303100), National Natural Science Foundation of China (82072881, 31570803 81773090), Natural Science Foundation of Shanghai (20ZR1409000), and Natural Science Foundation of Xinjiang Uygur Autonomous Region (2019D01C088).

Disclaimer All these study sponsors have no roles in the study design and in the collection, analysis, and interpretation of data.

Competing interests None declared.

Patient consent for publication Not required.

Ethics approval All samples used in this study were anonymously coded in accordance with Helsinki Declaration. Written informed consent was obtained from each patient included in this study, and the protocol of all study cohorts was approved by the Ethical Board of the Institutional Review Board of the Gynecology and Obstetrics Hospital of Fudan University (Kyy2016-49, Kyy2017-27).

Provenance and peer review Not commissioned; externally peer reviewed.

Data availability statement Data are available in a public, open access repository. All data relevant to the study are included in the article or uploaded as supplementary information. TCGA-OV ovarian cancer mRNA expression data from 340 cases with clinical data were downloaded from GDC legacy archive (https:// protal.gdc.cancer.gov/) in November 2017. All data generated that are relevant to the results presented in this article are included in this article.

Supplemental material This content has been supplied by the author(s). It has not been vetted by BMJ Publishing Group Limited (BMJ) and may not have been peer-reviewed. Any opinions or recommendations discussed are solely those of the author(s) and are not endorsed by BMJ. BMJ disclaims all liability and responsibility arising from any reliance placed on the content. Where the content includes any translated material, BMJ does not warrant the accuracy and reliability of the translations (including but not limited to local regulations, clinical guidelines, terminology, drug names and drug dosages), and is not responsible for any error and/or omissions arising from translation and adaptation or otherwise.

Open access This is an open access article distributed in accordance with the Creative Commons Attribution Non Commercial (CC BY-NC 4.0) license, which permits others to distribute, remix, adapt, build upon this work non-commercially, and license their derivative works on different terms, provided the original work is properly cited, appropriate credit is given, any changes made indicated, and the use is non-commercial. See http://creativecommons.org/licenses/by-nc/4.0/.

\section{ORCID iD}

Haiou Liu http://orcid.org/0000-0003-0200-8981

\section{CONCLUSION}

Our results demonstrate that CXCL13 confers antitumor effects via recruitment, activation, and expansion of 


\section{REFERENCES}

1 Bowtell DD, Böhm S, Ahmed AA, et al. Rethinking ovarian cancer II: reducing mortality from high-grade serous ovarian cancer. Nat Rev Cancer 2015;15:668-79.

2 Hamanishi J, Mandai M, Iwasaki M, et al. Programmed cell death 1 ligand 1 and tumor-infiltrating CD8+ T lymphocytes are prognostic factors of human ovarian cancer. Proc Natl Acad Sci U S A 2007;104:3360-5.

3 Disis ML, Taylor MH, Kelly K, et al. Efficacy and safety of Avelumab for patients with recurrent or refractory ovarian cancer: phase $1 \mathrm{~B}$ results from the javelin solid tumor trial. JAMA Oncol 2019;5:393-401.

$4 \mathrm{E}$ J, Yan F, Kang Z, et al. CD8 ${ }^{+} \mathrm{CXCR}^{+} \mathrm{T}$ cells in tumor-draining lymph nodes are highly activated and predict better prognosis in colorectal cancer. Hum Immunol 2018;79:446-52.

5 He R, Hou S, Liu C, et al. Follicular CXCR5- expressing CD8(+) T cells curtail chronic viral infection. Nature 2016;537:412-6.

6 Im SJ, Hashimoto M, Gerner MY, et al. Defining CD8+ T cells that provide the proliferative burst after PD-1 therapy. Nature 2016;537:417-21.

7 Brummelman J, Mazza EMC, Alvisi G, et al. High-dimensional single cell analysis identifies stem-like cytotoxic $\mathrm{CD}^{+} \mathrm{T}$ cells infiltrating human tumors. J Exp Med 2018;215:2520-35.

8 Bai M, Zheng Y, Liu H, et al. CXCR5 ${ }^{+} \mathrm{CD}^{+} \mathrm{T}$ cells potently infiltrate pancreatic tumors and present high functionality. Exp Cell Res 2017;361:39-45

9 Helmink BA, Reddy SM, Gao J, et al. B cells and tertiary lymphoid structures promote immunotherapy response. Nature 2020;577:549-55.

10 Cabrita R, Lauss M, Sanna A, et al. Tertiary lymphoid structures improve immunotherapy and survival in melanoma. Nature 2020;577:561-5.

11 Petitprez F, de Reyniès A, Keung EZ, et al. B cells are associated with survival and immunotherapy response in sarcoma. Nature 2020;577:556-60.

12 Tirosh I, Izar B, Prakadan SM, et al. Dissecting the multicellular ecosystem of metastatic melanoma by single-cell RNA-seq. Science 2016;352:189-96.

13 Gu-Trantien C, Loi S, Garaud S, et al. Cd4+ follicular helper $\mathrm{T}$ cell infiltration predicts breast cancer survival. $J$ Clin Invest 2013;123:2873-92.

14 Havenar-Daughton C, Lindqvist M, Heit A, et al. Cxcl13 is a plasma biomarker of germinal center activity. Proc Natl Acad Sci U S A 2016;113:2702-7.

15 Bindea G, Mlecnik B, Tosolini M, et al. Spatiotemporal dynamics of intratumoral immune cells reveal the immune landscape in human cancer. Immunity 2013;39:782-95.

16 Wei Y, Lin C, Li H, et al. Cxcl13 expression is prognostic and predictive for postoperative adjuvant chemotherapy benefit in patients with gastric cancer. Cancer Immunol Immunother 2018;67:261-9.

17 Byrne KT, Vonderheide RH. Cd40 stimulation obviates innate sensors and drives T cell immunity in cancer. Cell Rep 2016;15:2719-32.

18 Ovarian Tumor Tissue Analysis (OTTA) Consortium, Goode EL, Block MS, et al. Dose-response association of CD8+ tumor-infiltrating lymphocytes and survival time in high-grade serous ovarian cancer. JAMA Oncol 2017;3:e173290.

19 Lundgren S, Berntsson J, Nodin B, et al. Prognostic impact of tumour-associated B cells and plasma cells in epithelial ovarian cancer. J Ovarian Res 2016;9:9-21.

20 Ligeiro D, Trindade H, Lérias J. B cell structural diversity in early cultured tumor-infiltrating lymphocytes. J Immunother Cancer 2018;6:P2532018.

21 Nielsen JS, Sahota RA, Milne K, et al. CD20+ tumor-infiltrating lymphocytes have an atypical CD27- memory phenotype and together with CD8+ T cells promote favorable prognosis in ovarian cancer. Clin Cancer Res 2012;18:3281-92.

22 Kroeger DR, Milne K, Nelson BH. Tumor-Infiltrating plasma cells are associated with tertiary lymphoid structures, cytolytic T-cell responses, and superior prognosis in ovarian cancer. Clin Cancer Res 2016;22:3005-15.
23 Cyster JG, Ansel KM, Reif K, et al. Follicular stromal cells and lymphocyte homing to follicles. Immunol Rev 2000;176:181-93.

24 Thommen DS, Koelzer VH, Herzig P, et al. A transcriptionally and functionally distinct $\mathrm{PD}-1^{+} \mathrm{CD} 8^{+} \mathrm{T}$ cell pool with predictive potential in non-small-cell lung cancer treated with PD-1 blockade. Nat Med 2018;24:994-1004.

$25 \mathrm{Li} \mathrm{H}$, van der Leun AM, Yofe I, et al. Dysfunctional CD8 T cells form a proliferative, dynamically regulated compartment within human melanoma. Cell 2019;176:775-89.

26 Zheng C, Zheng L, Yoo J-K, et al. Landscape of infiltrating T cells in liver cancer revealed by single-cell sequencing. Cell 2017;169:1342-56

27 Gu-Trantien C, Migliori E, Buisseret L, et al. CXCL13-producing Tfh cells link immune suppression and adaptive memory in human breast cancer. JCI Insight 2017;2:e91487.

28 Carlsen HS, Baekkevold ES, Morton HC, et al. Monocyte-Like and mature macrophages produce $\mathrm{CXCL} 13$ (B cell-attracting chemokine 1) in inflammatory lesions with lymphoid neogenesis. Blood 2004;104:3021-7.

29 Litsiou E, Semitekolou M, Galani IE, et al. Cxcl13 production in B cells via Toll-like receptor/lymphotoxin receptor signaling is involved in lymphoid neogenesis in chronic obstructive pulmonary disease. Am J Respir Crit Care Med 2013;187:1194-202.

30 Kanemitsu N, Ebisuno Y, Tanaka T, et al. Cxcl13 is an arrest chemokine for B cells in high endothelial venules. Blood 2005;106:2613-8.

31 Ansel KM, Ngo VN, Hyman PL, et al. A chemokine-driven positive feedback loop organizes lymphoid follicles. Nature 2000;406:309-14.

32 Barone F, Nayar S, Campos J, et al. II-22 regulates lymphoid chemokine production and assembly of tertiary lymphoid organs. Proc Natl Acad Sci U S A 2015;112:11024-9.

$33 \mathrm{Kim} \mathrm{H}-\mathrm{J}$, Verbinnen B, Tang X, et al. Inhibition of follicular T-helper cells by CD8(+) regulatory T cells is essential for self tolerance. Nature 2010;467:328-32.

34 Leong YA, Chen Y, Ong HS, et al. CXCR5(+) follicular cytotoxic $\mathrm{T}$ cells control viral infection in B cell follicles. Nat Immunol 2016;17:1187-96.

35 Jin Y, Lang C, Tang J, et al. CXCR5 ${ }^{+} \mathrm{CD} 8^{+} \mathrm{T}$ cells could induce the death of tumor cells in HBV-related hepatocellular carcinoma. Int Immunopharmacol 2017;53:42-8.

36 Xing J, Zhang C, Yang X, et al. CXCR5 ${ }^{+} \mathrm{CD}^{+} \mathrm{T}$ cells infiltrate the colorectal tumors and nearby lymph nodes, and are associated with enhanced IgG response in B cells. Exp Cell Res 2017;356:57-63.

37 Utzschneider DT, Charmoy M, Chennupati V, et al. T cell factor 1-expressing Memory-like CD8(+) T cells sustain the immune response to chronic viral infections. Immunity 2016;45:415-27.

38 Man K, Gabriel SS, Liao Y, et al. Transcription factor IRF4 promotes $\mathrm{CD}^{+} \mathrm{T}$ cell exhaustion and limits the development of Memory-like T cells during chronic infection. Immunity 2017;47:1129-41.

39 Shan Q, Zeng Z, Xing S, et al. The transcription factor Runx3 guards cytotoxic CD8 ${ }^{+}$effector T cells against deviation towards follicular helper T cell lineage. Nat Immunol 2017;18:931-9.

40 Danilo M, Chennupati V, Silva JG, et al. Suppression of Tcf1 by Inflammatory Cytokines Facilitates Effector CD8 T Cell Differentiation. Cell Rep 2018;22:2107-17.

$41 \mathrm{Wu}$ T, Ji Y, Moseman EA, et al. The TCF1-Bcl6 axis counteracts type I interferon to repress exhaustion and maintain T cell stemness. Sci Immunol 2016;1:eaai8593.

42 Huang Z, Zak J, Pratumchai I, et al. IL-27 promotes the expansion of self-renewing $\mathrm{CD}^{+} \mathrm{T}$ cells in persistent viral infection. J Exp Med 2019;216:1791-808

43 Huang $\mathrm{Q}$, Zhou $\mathrm{Q}$, Zhang $\mathrm{H}$, et al. Identification and validation of an excellent prognosis subtype of muscle-invasive bladder cancer patients with intratumoral $\mathrm{CXCR}^{+} \mathrm{CD} 8^{+} \mathrm{T}$ cell abundance. Oncoimmunology 2020;9:1810489.

44 Ferrando-Martinez S, Moysi E, Pegu A, et al. Accumulation of follicular CD8+ T cells in pathogenic SIV infection. J Clin Invest 2018;128:2089-103.

45 Kang YM, Zhang X, Wagner UG, et al. Cd8 T cells are required for the formation of ectopic germinal centers in rheumatoid synovitis. J Exp Med 2002;195:1325-36. 